\title{
Minireview
}

\section{Targeting lymphangiogenesis to prevent tumour metastasis}

\author{
MG Achen ${ }^{*, 1}$, GB Mann² and SA Stacker ${ }^{*, 1}$ \\ 'Ludwig Institute for Cancer Research, Post Office Box 2008 Royal Melbourne Hospital, Victoria 3050, Australia; ${ }^{2}$ Department of Surgery, The Royal \\ Melboume Hospital, University of Melbourne, Parkville 3050, Victoria, Australia
}

Recent studies involving animal models of cancer and clinicopathological analyses of human tumours suggest that the growth of lymphatic vessels (lymphangiogenesis) in or nearby tumours is associated with the metastatic spread of cancer. The best validated molecular signalling system for tumour lymphangiogenesis involves the secreted proteins vascular endothelial growth factor-C (VEGFC) and VEGF-D that induce growth of lymphatic vessels via activation of VEGF receptor-3 (VEGFR-3) localised on the surface of lymphatic endothelial cells. In this review, we discuss the evidence supporting a role for this signalling system in the spread of cancer and potential approaches for blocking this system to prevent tumour metastasis.

British Journal of Cancer (2006) 94, I355-1360. doi: I0.1038/sj.bjc.6603I 20 www.bjcancer.com

Published online 25 April 2006

(C) 2006 Cancer Research UK

Keywords: inhibitor; lymphatic vessel; VEGF-C; VEGF-D; VEGFR-3

The lymphatic vasculature is an important route for the metastatic spread of human cancer. Hence, in almost all carcinomas, the presence of tumour foci in lymph nodes is the most important adverse prognostic factor in apparently localised disease. Furthermore, inhibition of regional lymph nodal metastasis was associated with reduced distant organ metastasis in some animal models suggesting a pathway may exist for distant organ metastasis via the lymph nodes (e.g. see Krishnan et al, 2003). It was previously thought that lymphatic metastasis involved passage of malignant cells along pre-existing lymphatic vessels near a tumour, however, recent studies in animal models suggest that lymphangiogenesis can be induced by solid tumours and may promote tumour spread (for a review see Saharinen et al, 2004). Moreover, clinicopathological studies have revealed that lymphangiogenesis can occur adjacent to or within human cancers and that this correlates with metastasis to lymph nodes in some tumour types including head and neck cancer (Beasley et al, 2002) and cutaneous melanoma (Dadras et al, 2003) (Table 1). The location of tumour lymphatics may be an important issue for metastatic spread as some studies have indicated that intratumoural lymphatic vessels are nonfunctional and that peritumoural lymphatics are more important for this process (e.g. see Padera et al, 2002). The extensive experimental and clinicopathological studies of tumour lymphangiogenesis carried out over the past 5 years suggest that it may be a useful target for therapeutics designed to restrict cancer metastasis.

The best validated signalling system for tumour lymphangiogenesis involves the secreted glycoproteins VEGF-C and VEGF-D that signal via VEGF receptor-3 (VEGFR-3; also known as Flt4), expressed on the surface of lymphatic endothelial cells (Joukov

\footnotetext{
* Correspondence: Associate Professor MG Achen or Associate Professor SA Stacker;

E-mails: Marc.achen@ludwig.edu.au, Steven.stacker@ludwig.edu.au Received 27 January 2006; revised 20 March 2006; accepted 29 March 2006; published online 25 April 2006
}

et al, 1996; Achen et al, 1998; Veikkola et al, 2001). Vascular endothelial growth factor-C and VEGF-D have been shown to promote tumour lymphangiogenesis, the metastatic spread of tumour cells to lymph nodes and, in some cases, distant organ metastasis in multiple animal models of cancer (for a review see Saharinen et al, 2004). Furthermore, expression of these growth factors appears to correlate with lymph node metastasis in numerous common human cancers (for a review see Stacker et al, 2002a). Other protein growth factors that have also been implicated in tumour lymphangiogenesis are platelet-derived growth factors (PDGFs) (Cao et al, 2004) and VEGF-A (Hirakawa et al, 2005), however, the evidence for involvement of these molecules in tumour lymphangiogenesis is currently restricted to relatively few animal models and therefore requires analysis in a broader range of experimental models as well as extensive clinicopathological studies to correlate the expression of these molecules with metastasis in human cancer. In summary, the VEGF-C/VEGF-D/VEGFR-3 signalling system is currently the most attractive target for antilymphangiogenic therapeutics designed to restrict cancer metastasis, although it is likely that other validated targets will emerge in future. We therefore focus on the VEGF-C/ VEGF-D/VEGFR-3 signalling system in this article.

\section{VEGF-C/VEGF-D/VEGFR-3 SIGNALLING AND TUMOUR METASTASIS}

\section{Mechanisms of lymphangiogenic signalling}

The lymphangiogenic growth factors VEGF-C and VEGF-D are synthesised as proproteins consisting of a central VEGF homology domain (VHD), containing receptor-binding sites, flanked by $\mathrm{N}$ and C-terminal propeptides (Joukov et al, 1996; Achen et al, 1998). Subsequently, the propeptides can be proteolytically removed to generate mature forms consisting of VHD dimers. The full-length forms of both growth factors bind the lymphangiogenic receptor VEGFR-3 but the mature forms do so with greater affinity (Joukov 
Table I Human cancers in which lymphangiogenesis has been observed

\begin{tabular}{|c|c|c|c|}
\hline Cancer & $\begin{array}{l}\text { Type of } \\
\text { lymphangiogenesis: } \\
\text { IT or } \mathrm{PT}^{\mathrm{a}}\end{array}$ & $\begin{array}{l}\text { Is lymph node metastasis correlated with } \\
\text { lymphangiogenesis? }\end{array}$ & Reference \\
\hline Head and neck cancer & IT and PT & Yes, with both IT and PT & (Beasley et al, 2002; Franchi et al, 2004) \\
\hline Colorectal cancer & IT & Yes, with IT & (Kuroyama et al, 2005) \\
\hline Cutaneous melanoma ${ }^{b}$ & IT and PT & Yes, with both IT and PT & (Dadras et al, 2003) \\
\hline Non-small-cell lung cancer & Predominantly PT & Yes, with PT & (Renyi-Vamos et al, 2005) \\
\hline Gastric cancer & $\mathrm{IT}$ and $\mathrm{PT}$ & $\begin{array}{l}\text { Yes, but type of lymphangiogenesis correlated with metastasis } \\
\text { was not defined }\end{array}$ & (Nakamura et al, 2006) \\
\hline Cancer of the uterine cervix & $\mathrm{IT}$ and $\mathrm{PT}$ & Yes, with PT only & (Gombos et al, 2005) \\
\hline Breast cancer $^{b}$ & PT & $\begin{array}{l}\text { No, lymph node metastasis correlated with tumour invasion of } \\
\text { lymphatics, not with lymphatic vessel density }\end{array}$ & (Schoppmann et al, 2004) \\
\hline Papillary thyroid cancer & IT (PT not analysed) & Yes, with IT & (Hall et al, 2003) \\
\hline
\end{tabular}

${ }^{\mathrm{a}} \mathrm{T}$ denotes intratumoural and PT denotes peritumoural. ${ }^{\mathrm{b}}$ There has been at least one report disputing that lymphangiogenesis occurs in this tumour type.

et al, 1997; Stacker et al, 1999), suggesting that the degree of proteolytic processing of VEGF-C and VEGF-D may in part determine the extent of lymphangiogenesis induced by these proteins in a tumour. Once VEGF-C is processed to the mature form it acquires the capacity to bind VEGFR-2 (Joukov et al, 1997), a cell surface receptor tyrosine kinase thought to signal for angiogenesis. In the case of VEGF-D, the affinity for VEGFR-2 is increased approximately 290 -fold by proteolytic conversion of the full-length to the mature form (Stacker et al, 1999). Hence the mature forms of VEGF-C and VEGF-D can induce angiogenesis (Cao et al, 1998; Rissanen et al, 2003). The enzymes known to process VEGF-C or VEGF-D are the serine protease plasmin (McColl et al, 2003) and members of proprotein convertase (PC) family, namely furin, PC5 and PC7 (Siegfried et al, 2003). Plasmin also cleaves some isoforms of the angiogenic growth factor VEGFA, releasing them from the extracellular matrix or cell surface thus making them available for inducing angiogenesis (Houck et al, 1992). The PCs have also been implicated in activation of other growth factors involved in lymphangiogenesis or angiogenesis, such as PDGFs (Siegfried et al, 2005). Hence these proteases could play a broad role in regulating growth of lymphatics and blood vessels in cancer.

As is the case for receptor tyrosine kinases in general, activation of VEGFR-3 by its ligands VEGF-C or VEGF-D results in transphosphorylation of tyrosine residues in the cytoplasmic domains of the dimerised receptor (Dixelius et al, 2003). Such phosphorylation events are known to be critical for the regulation of receptor kinase activity and for receptor interactions with signal transduction molecules. Analysis of VEGFR-3 signalling in lymphatic endothelial cells in culture indicated that activation of VEGFR-3 alone was sufficient to protect the cells from apoptosis and to induce proliferation and migration (Makinen et al, 2001). At least some of these signals were transduced by protein kinase Cdependent activation of the p42/p44 MAPK signalling cascade and via induction of Akt phosphorylation, two important signalling systems known to be associated with cell growth and survival. Further aspects of the VEGFR-3 signalling pathways remain to be elucidated and may be more complex than originally thought given that VEGFR-3 has been reported to form heterodimers with VEGFR-2 (Dixelius et al, 2003).

\section{Lymphangiogenic signalling and tumour metastasis}

A range of experimental studies in animal models demonstrated that the VEGF-C/VEGF-D/VEGFR-3 signalling axis can promote tumour lymphangiogenesis and the metastatic spread of tumour cells. One approach has involved expressing VEGF-C or VEGF-D in tumour cells and monitoring the effects on lymphatic vessels within or adjacent to solid tumours as well as assessing the degree to which tumour cells spread to lymph nodes. For example, expression of VEGF-C in breast cancer cells increased intratumoural lymphangiogenesis and metastasis to lymph nodes and lung after injection into mice (Skobe et al, 2001b). In other models, expression of VEGF-C in breast cancer cells promoted growth of tumour-associated lymphatics (Skobe et al, 2001a), that were in some cases infiltrated with tumour cells (Karpanen et al, 2001), and metastatic spread to lymph nodes (Mattila et al, 2002). In a transgenic mouse model of pancreatic cancer, expression of VEGF-C in tumour cells led to extensive lymphangiogenesis associated with the tumours and metastases in draining lymph nodes (Mandriota et al, 2001). Expression of VEGF-D in tumour cells of a mouse xenograft model promoted formation of intratumoural lymphatics, angiogenesis, tumour growth and metastasis to lymph nodes (Stacker et al, 2001). The lymphatic metastasis in this model was prevented by a neutralising VEGF-D antibody that blocked binding of this growth factor to both VEGFR-2 and VEGFR-3 (Achen et al, 2000; Stacker et al, 2001). Further, VEGF-D promoted tumour lymphangiogenesis and lymphatic metastasis in mouse models of pancreatic cancer (Von Marschall et al, 2005).

An alternative approach for assessing the role of the VEGF-C/ VEGF-D/VEGFR-3 system in cancer metastasis has been to treat well-established animal models of tumour spread, that have not been genetically engineered to express VEGF-C or VEGF-D, with inhibitors of this signalling pathway and to monitor the effects on lymphatic and distant organ metastases. For example, the highly metastatic human lung cancer cell line NCI-H460-LNM35 was transfected with an expression construct for a soluble version of VEGFR-3 (soluble VEGFR-3) that binds VEGF-C and thereby inhibits signalling by endogenous VEGFR-3 (He et al, 2002). The resulting tumour xenografts in mice contained fewer intratumoural lymphatic vessels and there were less metastases in draining lymph nodes than for control tumours that did not express soluble VEGFR-3. Mice with control NCI-H460-LNM35 tumours (i.e. not expressing soluble VEGFR-3) were treated with recombinant adenovirus expressing soluble VEGFR-3 as an alternative inhibitory strategy - this also restricted lymph node metastasis (He et al, 2002). In another animal model, expression of a soluble VEGFR-3 in highly metastatic MT-450 mammary tumour cells suppressed metastasis formation both in the regional lymph nodes and the lungs of rats (Krishnan et al, 2003). More recently, a recombinant adeno-associated virus expressing a soluble VEGFR-3 was shown to inhibit lymph node metastasis in a melanoma model in mice (Lin et al, 2005) and inhibition of VEGF-C expression using small interfering RNA-mediated gene silencing reduced lymphangiogenesis, lymph node metastasis and spontaneous lung metastasis in a mouse mammary tumour model (Chen et al, 2005). However, inhibition of tumour lymphangiogenesis using a soluble 
VEGFR-3 was not sufficient to block lymph node metastasis in a mouse model of prostate cancer suggesting that lymphangiogenesis is not an essential requirement for lymphatic spread in all tumours (Wong et al, 2005).

Clinicopathological studies carried out over the past 7 years have reported that expression of VEGF-C, VEGF-D or VEGFR-3 can correlate with lymph node metastasis in human cancer, a topic that has been extensively reviewed in recent times (Stacker et al, 2002a, b; He et al, 2004). According to some of these studies, VEGF-C expression in tumour cells correlates with lymph node metastasis in lung, colorectal and prostate cancer (for review see Stacker et al, 2004) and may be a prognostic factor in ovarian and cervical cancer (Ueda et al, 2002; Nishida et al, 2004). Vascular endothelial growth factor-D expression was reported to be associated with lymphatic involvement and a prognostic marker in colorectal cancer (White et al, 2002) and a predictor of poor outcome in epithelial ovarian carcinoma (Yokoyama et al, 2003). Interestingly, VEGF-D and VEGFR-3 were recently reported to be independent prognostic markers in gastric adenocarcinoma and the presence of VEGF-D was correlated with lymphatic metastases in this tumour type (Juttner et al, 2006). There have been many reports of human tumours in which tumour cells express lymphangiogenic growth factors, but it is important to note that tumour-associated inflammatory cells, such as macrophages, can also express VEGF-C and VEGF-D, and could thereby play an important role in tumour lymphangiogenesis (Schoppmann et al, 2002).

\section{TARGETING THE VEGF-C/VEGF-D/VEGFR-3 SIGNALLING AXIS}

The approach for targeting the VEGF-C/VEGF-D/VEGFR-3 pathway that has been most extensively employed in animal models of cancer, but is yet to be tested in the clinic, is the use of soluble versions of VEGFR-3 that bind VEGF-C and VEGF-D, thereby inhibiting activation of endogenous VEGFR-3 (see previous section) (He et al, 2002; Krishnan et al, 2003; Lin et al, 2005). It is yet to be determined if a soluble VEGFR-3 construct binds VEGF-C and VEGF-D so that these growth factors are also unable to activate endogenous VEGFR-2 - if this were the case soluble VEGFR-3 would have the merit of preventing the contribution made by these growth factors to angiogenic signalling in cancer via VEGFR-2 as well as lymphangiogenic signalling via VEGFR-3. Soluble versions of cell surface receptors are already used in clinical medicine, such as Enbrel ${ }^{\mathbb{R}}$ (also known as etanercept), a recombinant soluble version of the p75 receptor for tumour necrosis factor, that is used to treat rheumatoid arthritis (for a review see Maini and Taylor, 2000).

Other potential antilymphangiogenic therapeutics that would not enter the cell includes monoclonal antibodies to VEGF-C and VEGF-D, which block binding to both VEGFR-2 and VEGFR-3. Such an antibody to VEGF-D has already been described (Achen et al, 2000) and was shown to block angiogenesis, lymphangiogenesis and lymph node metastasis in a VEGF-D-dependent mouse tumour model (Stacker et al, 2001). Monoclonal antibodies to VEGFR-3 that block the binding of VEGF-C and VEGF-D could also be effective. Such an antibody to VEGFR-3 has been shown to block regeneration of adult lymphatic vessels (Pytowski et al, 2005) but its effects in cancer have not been reported. This type of reagent would not block activation of VEGFR-2 by VEGF-C or VEGF-D, however, bispecific antibodies that bind both VEGFR-2 and VEGFR-3 (Jimenez et al, 2005) could possibly be used for this purpose. Monoclonal antibodies are well established as anticancer therapeutics, one example being an antibody to VEGF-A, known as bevacizumab or Avastin ${ }^{\mathbb{R}}$, that is designed to restrict tumour angiogenesis and used to treat patients with metastatic colorectal cancer (Ferrara et al, 2004).
An alternative strategy to receptor constructs and antibodies involves small molecules that enter the cell such as inhibitors of the VEGFR-3 tyrosine kinase or of downstream signalling molecules. A range of small molecules has been shown to inhibit the VEGFR-3 kinase, in addition to multiple other kinases such as VEGFR-2, some of which are in clinical trials as anticancer therapeutics - these include BAY 43-9006, CEP-7055 and PTK787/ ZK 222584 (for a review see Achen et al, 2005). The signalling mechanisms downstream of activated VEGFR-3 are inadequately understood to justify targeting this component of lymphangiogenic signalling at this stage.

How might an antimetastatic therapy, based on inhibiting tumour lymphangiogenesis, be utilised in the clinic? The management of most solid tumours involves surgical removal of the primary cancer to achieve local disease control and to restrict further metastatic spread. In cancers where effective systemic therapies are available, patients with tumour characteristics indicating there is a moderate to high risk of subsequent distant relapse are offered adjuvant therapy (Sun and Haller, 2005). This is usually in the form of cytotoxic chemotherapy, or some form of endocrine manipulation. Recently there has been intense investigation of the use of systemic therapies before surgery (Wolmark et al, 2001). This has been widely used to reduce the size of the primary cancer to facilitate surgery, for example by making a borderline resectible tumour more easily resectible, or to allow breast conservation for a tumour that would otherwise have required a mastectomy (Wolmark et al, 2001). More recently, there have been examples suggesting an improved cancer outcome with a preoperative approach (Malthaner and Fenlon, 2003). An antilymphangiogenic approach could be used in conjunction with conventional chemotherapy regimens in these scenarios (Figure 1), and may possibly reduce the incidence of local or distant recurrence. Treatment of advanced, nonresectible cancer remains inadequate in almost all cancers, and antilymphangiogenic agents may have a role in combination with other systemic agents in this scenario.

Several criteria should be met before introducing antilymphangiogenic agents to clinical trials. Reliable assays to detect the presence of VEGF-C, VEGF-D and VEGFR-3, and also to detect intra- or peritumoural lymphangiogenesis must be in place. Approaches for detecting these by immunohistochemistry, including identification of lymphatic vessels by staining for markers such as LYVE-1 (Dadras et al, 2003) and podoplanin (Renyi-Vamos et al, 2005), have been described in the clinicopathological literature and may require further development to become sufficiently robust. Initial trials should be performed on cancers in which lymphangiogenesis can be detected in a reasonable proportion of cases. Repeat biopsy and reassay after treatment is also important for the purposes of trials. While initial trials may be performed with patients with advanced disease, the neoadjuvant setting may yield the best results. Further work on tissue-banked specimens from breast, colorectal, esophago-gastric, lung and head and neck cancer specimens may identify the best candidate cancers, but ultimately it will require careful clinical trials with biological as well as clinical end points to assess this approach.

\section{CONCLUDING REMARKS}

There is considerable experimental and clinicopathological evidence suggesting that tumour lymphangiogenesis is associated with the metastatic spread of cancer. Moreover, studies in experimental models of cancer have demonstrated that the VEGF-C/VEGF-D/VEGFR-3 signalling system is a key regulator of tumour lymphangiogenesis. This is further supported by clinicopathological analyses of human cancer showing that expression of VEGF-C and VEGF-D can correlate with lymph node metastasis in some human cancers. Numerous reagents that 
Timeline of treatment

Preoperative treatment

Antilymphangiogenesis

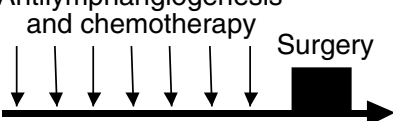

Postoperative treatment

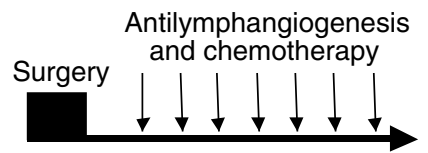

Advanced disease

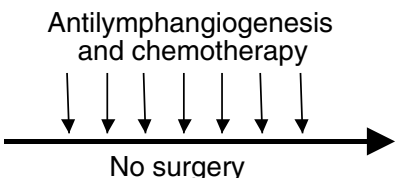

Aim

Relevant cancers
Breast cancer (L,C,D)

Gastric cancer (L,D)

Colorectal cancer (L,C,D) treatment designed to

facilitate surgery
Restrict metastasis after surgery in patients with high risk of relapse

\author{
Breast cancer (L,C,D) \\ Melanoma (L,C)
}

\author{
Restrict progression of \\ disease in nonresectible \\ cancer
}

\author{
Breast cancer (L,C,D) \\ Melanoma (L,C) \\ Colorectal cancer (L,C,D)
}

Figure I Clinical settings in which an antilymphangiogenic therapeutic agent, designed to restrict tumour metastasis, may be useful. Three scenarios are shown: top, during preoperative chemotherapy; middle, as part postoperative adjuvant therapy for patients with high risk for subsequent recurrence; bottom, during palliative systemic therapy of advanced tumours. In all cases it is envisaged that the antilymphangiogenic agent would most likely be effective in combination with cytotoxic chemotherapy. The course of each treatment is shown schematically to the left and the aim is listed in the central column. Human cancers for which these scenarios occur commonly are shown to the right with letters in parentheses denoting the following: 'L' that lymphangiogenesis has been associated with this tumour type; ' $C$ ' that for this tumour type VEGF-C expression has been reported to correlate with lymph node metastasis in at least one study; 'D' that for this tumour type VEGF-D expression has been reported to correlate with lymph node metastasis in at least one study (see Table I and Stacker et al, 2004).

could be used to block this pathway already exist, including soluble VEGFR-3 protein constructs, neutralising monoclonal antibodies to VEGFR-3 and VEGF-D, and small molecule inhibitors of the VEGFR-3 kinase. Some of these reagents should also block the contribution of VEGF-C and VEGF-D to tumour angiogenesis via VEGFR-2, which could provide added benefit for patients. Hence, it is now appropriate to test this approach in the clinic. Some of the small molecule VEGFR-3 inhibitors are already in clinical trials, however, these trials are not specifically designed to monitor effects on metastasis. Indeed, clinical testing of an antimetastatic approach to cancer may require new strategies for trials so that the occurrence of cancer metastases can be monitored. Nevertheless, clinical testing of this approach is warranted in the near future.

\section{ACKNOWLEDGEMENTS}

MGA and SAS are supported by Senior Research Fellowships from the National Health and Medical Research Council of Australia (NHMRC) and the Pfizer Foundation, respectively, and by a Program Grant from the NHMRC. We thank Ramin Shayan and Tony Burgess for helpful comments and acknowledge researchers whose work could not be cited here due to space restrictions.

\section{REFERENCES}

Achen MG, Jeltsch M, Kukk E, Mäkinen T, Vitali A, Wilks AF, Alitalo K, Stacker SA (1998) Vascular endothelial growth factor D (VEGF-D) is a ligand for the tyrosine kinases VEGF receptor 2 (Flk-1) and VEGF receptor 3 (Flt-4). Proc Natl Acad Sci USA 95: 548-553

Achen MG, McColl BK, Stacker SA (2005) Focus on lymphangiogenesis in tumor metastasis. Cancer Cell 7: 121-127

Achen MG, Roufail S, Domagala T, Catimel B, Nice EC, Geleick DM, Murphy R, Scott AM, Caesar C, Makinen T, Alitalo K, Stacker SA (2000) Monoclonal antibodies to vascular endothelial growth factor-D block interactions with both VEGF receptor-2 and VEGF receptor-3. Eur $J$ Biochem 267: 2505-2515

Beasley NJP, Prevo R, Banerji S, Leek RD, Moore J, van Trappen P, Cox G, Harris AL, Jackson DG (2002) Intratumoral lymphangiogenesis and lymph node metastasis in head and neck cancer. Cancer Res 62: $1315-1320$
Cao R, Bjorndahl MA, Religa P, Clasper S, Garvin S, Galter D, Meister B, Ikomi F, Tritsaris K, Dissing S, Ohhashi T, Jackson DG, Cao Y (2004) PDGF-BB induces intratumoral lymphangiogenesis and promotes lymphatic metastasis. Cancer Cell 6: 333-345

Cao Y, Linden P, Farnebo J, Cao R, Eriksson A, Kumar V, Qi JH, Claesson-Welsh L, Alitalo K (1998) Vascular endothelial growth factor C induces angiogenesis in vivo. Proc Natl Acad Sci USA 95: $14389-14394$

Chen Z, Varney ML, Backora MW, Cowan K, Solheim JC, Talmadge JE, Singh RK (2005) Down-regulation of vascular endothelial cell growth factor-C expression using small interfering RNA vectors in mammary tumors inhibits tumor lymphangiogenesis and spontaneous metastasis and enhances survival. Cancer Res 65: 9004-9011

Dadras SS, Paul T, Bertoncini PT, Brown LF, Muzikansky A, Jackson DG, Ellwanger U, Garbe C, Mihm MC, Detmar M (2003) Tumor lymphangio- 
genesis: a novel prognostic indicator for cutaneous melanoma metastasis and survival. Am J Pathol 162: $1951-1960$

Dixelius J, Makinen T, Wirzenius M, Karkkainen MJ, Wernstedt C, Alitalo K, Claesson-Welsh L (2003) Ligand-induced vascular endothelial growth factor receptor-3 (VEGFR-3) heterodimerization with VEGFR-2 in primary lymphatic endothelial cells regulates tyrosine phosphorylation sites. J Biol Chem 278: 40973-40979

Ferrara N, Hillan KJ, Gerber HP, Novotny W (2004) Discovery and development of bevacizumab, an anti-VEGF antibody for treating cancer. Nat Rev Drug Discov 3: 391 - 400

Franchi A, Gallo O, Massi D, Baroni G, Santucci M (2004) Tumor lymphangiogenesis in head and neck squamous cell carcinoma: a morphometric study with clinical correlations. Cancer 101: 973-978

Gombos Z, Xu X, Chu CS, Zhang PJ, Acs G (2005) Peritumoral lymphatic vessel density and vascular endothelial growth factor $\mathrm{C}$ expression in early-stage squamous cell carcinoma of the uterine cervix. Clin Cancer Res 11: $8364-8371$

Hall FT, Freeman JL, Asa SL, Jackson DG, Beasley NJ (2003) Intratumoral lymphatics and lymph node metastases in papillary thyroid carcinoma. Arch Otolaryngol Head Neck Surg 129: 716-719

He Y, Karpanen T, Alitalo K (2004) Role of lymphangiogenic factors in tumor metastasis. Biochim Biophys Acta 1654: 3-12

He Y, Kozaki K, Karpanen T, Koshikawa K, Yla-Herttuala S, Takahashi T, Alitalo K (2002) Suppression of tumor lymphangiogenesis and lymph node metastasis by blocking vascular endothelial growth factor receptor 3 signaling. J Natl Cancer Inst 94: 819-825

Hirakawa S, Kodama S, Kunstfeld R, Kajiya K, Brown LF, Detmar M (2005) VEGF-A induces tumor and sentinel lymph node lymphangiogenesis and promotes lymphatic metastasis. J Exp Med 201: 1089-1099

Houck KA, Leung DW, Rowland AM, Winer J, Ferrara N (1992) Dual regulation of vascular endothelial growth factor bioavailability by genetic and proteolytic mechanisms. J Biol Chem 267: 26031-26037

Jimenez X, Lu D, Brennan L, Persaud K, Liu M, Miao H, Witte L, Zhu Z (2005) A recombinant, fully human, bispecific antibody neutralizes the biological activities mediated by both vascular endothelial growth factor receptors 2 and 3. Mol Cancer Ther 4: 427-434

Joukov V, Pajusola K, Kaipainen A, Chilov D, Lahtinen I, Kukk E, Saksela O, Kalkkinen N, Alitalo K (1996) A novel vascular endothelial growth factor, VEGF-C, is a ligand for the Flt-4 (VEGFR-3) and KDR (VEGFR-2) receptor tyrosine kinases. EMBO J 15: 290-298

Joukov V, Sorsa T, Kumar V, Jeltsch M, Claesson-Welsh L, Cao Y, Saksela O, Kalkkinen N, Alitalo K (1997) Proteolytic processing regulates receptor specificity and activity of VEGF-C. EMBO J 16: 3898-3911

Juttner S, Wissmann C, Jons T, Vieth M, Hertel J, Gretschel S, Schlag PM, Kemmner W, Hocker M (2006) Vascular endothelial growth factor-D and its receptor VEGFR-3: two novel independent prognostic markers in gastric adenocarcinoma. J Clin Oncol 24: 228-240

Karpanen T, Egeblad M, Karkkainen MJ, Kubo H, Ylä-Herttuala S, Jäättel M, Alitalo K (2001) Vascular endothelial growth factor C promotes tumor lymphangiogenesis and intralymphatic tumor growth. Cancer Res 61: $1786-1790$

Krishnan J, Kirkin V, Steffen A, Hegen M, Weih D, Tomarev S, Wilting J, Sleeman JP (2003) Differential in vivo and in vitro expression of vascular endothelial growth factor (VEGF)-C and VEGF-D in tumors and its relationship to lymphatic metastasis in immunocompetent rats. Cancer Res 63: $713-722$

Kuroyama S, Kobayashi N, Ohbu M, Ohtani Y, Okayasu I, Kakita A (2005) Enzyme histochemical analysis of lymphatic vessels in colon carcinoma: occurrence of lymphangiogenesis within the tumor. Hepatogastroenterol 52: $1057-1061$

Lin J, Lalani AS, Harding TC, Gonzalez M, Wu WW, Luan B, Tu GH, Koprivnikar K, VanRoey MJ, He Y, Alitalo K, Jooss K (2005) Inhibition of lymphogenous metastasis using adeno-associated virus-mediated gene transfer of a soluble VEGFR-3 decoy receptor. Cancer Res 65: 6901 - 6909

Maini RN, Taylor PC (2000) Anti-cytokine therapy for rheumatoid arthritis. Annu Rev Med 51: $207-229$

Makinen T, Veikkola T, Mustjoki S, Karpanen T, Catimel B, Nice EC, Wise L, Mercer A, Kowalski H, Kerjaschki D, Stacker SA, Achen MG, Alitalo K (2001) Isolated lymphatic endothelial cells transduce growth, survival and migratory signals via the VEGF-C/D receptor VEGFR-3. EMBO J 20: $4762-4773$

Malthaner R, Fenlon D (2003) Preoperative chemotherapy for resectable thoracic esophageal cancer. Cochrane Database Syst Rev CD001556

Mandriota SJ, Jussila L, Jeltsch M, Compagni A, Baetens D, Prevo R, Banerji S, Huarte J, Montesano R, Jackson DG, Orci L, Alitalo K, Christofori G,
Pepper MS (2001) Vascular endothelial growth factor-Cmediated lymphangiogenesis promotes tumour metastasis. EMBO J 20: $672-682$

Mattila MM, Ruohola JK, Karpanen T, Jackson DG, Härkönen PL (2002) VEGF-C induced lymphangiogenesis is associated with lymph node metastasis in orthotopic MCF-7 tumours. Int J Cancer 98: 946-951

McColl BK, Baldwin ME, Roufail S, Freeman C, Moritz RL, Simpson RJ, Alitalo K, Stacker SA, Achen MG (2003) Plasmin activates the lymphangiogenic growth factors VEGF-C and VEGF-D. J Exp Med 198: $863-868$

Nakamura Y, Yasuoka H, Tsujimoto M, Kurozumi K, Nakahara M, Nakao K, Kakudo K (2006) Importance of lymph vessels in gastric cancer: a prognostic indicator in general and a predictor for lymph node metastasis in early stage cancer. J Clin Pathol 59: 77-82

Nishida N, Yano H, Komai K, Nishida T, Kamura T, Kojiro M (2004) Vascular endothelial growth factor $\mathrm{C}$ and vascular endothelial growth factor receptor 2 are related closely to the prognosis of patients with ovarian carcinoma. Cancer 101: $1364-1374$

Padera TP, Kadambi A, di Tomaso E, Carreira CM, Brown EB, Boucher Y, Choi NC, Mathisen D, Wain J, Mark EJ, Munn LL, Jain RK (2002) Lymphatic metastasis in the absence of functional intratumor lymphatics. Science 296: $1883-1886$

Pytowski B, Goldman J, Persaud K, Wu Y, Witte L, Hicklin DJ, Skobe M, Boardman KC, Swartz MA (2005) Complete and specific inhibition of adult lymphatic regeneration by a novel VEGFR-3 neutralizing antibody. I Natl Cancer Inst 97: 14-21

Renyi-Vamos F, Tovari J, Fillinger J, Timar J, Paku S, Kenessey I, Ostoros G, Agocs L, Soltesz I, Dome B (2005) Lymphangiogenesis correlates with lymph node metastasis, prognosis, and angiogenic phenotype in human non-small cell lung cancer. Clin Cancer Res 11: 7344-7353

Rissanen TT, Markkanen JE, Gruchala M, Heikura T, Puranen A, Kettunen MI, Kholov I, Kauppinen RA, Achen MG, Stacker SA, Alitalo K, YläHerttuala S (2003) VEGF-D is the strongest angiogenic and lymphangiogenic effector among VEGFs delivered into skeletal muscle via adenoviruses. Circ Res 92: 1098-1106

Saharinen P, Tammela T, Karkkainen MJ, Alitalo K (2004) Lymphatic vasculature: development, molecular regulation and role in tumor metastasis and inflammation. Trends Immunol 25: 387-395

Schoppmann SF, Bayer G, Aumayr K, Taucher S, Geleff S, Rudas M, Kubista E, Hausmaninger H, Samonigg H, Gnant M, Jakesz R, Horvat R (2004) Prognostic value of lymphangiogenesis and lymphovascular invasion in invasive breast cancer. Ann Surg 240: 306-312

Schoppmann SF, Birner P, Stockl J, Kalt R, Ullrich R, Caucig C, Kriehuber E, Nagy K, Alitalo K, Kerjaschki D (2002) Tumor-associated macrophages express lymphatic endothelial growth factors and are related to peritumoral lymphangiogenesis. Am J Pathol 161: 947-956

Siegfried G, Basak A, Cromlish JA, Benjannet S, Marcinkiewicz J, Chrétien M, Seidah NG, Khatib A-M (2003) The secretory proprotein convertases furin, PC5, and PC7 activate VEGF-C to induce tumorigenesis. J Clin Invest 111: $1723-1732$

Siegfried G, Basak A, Prichett-Pejic W, Scamuffa N, Ma L, Benjannet S, Veinot JP, Calvo F, Seidah N, Khatib AM (2005) Regulation of the stepwise proteolytic cleavage and secretion of PDGF-B by the proprotein convertases. Oncogene 24: 6925-6935

Skobe M, Hamberg LM, Hawighorst T, Schirner M, Wolf GL, Alitalo K, Detmar M (2001a) Concurrent induction of lymphangiogenesis, angiogenesis, and macrophage recruitment by vascular endothelial growth factor-C in melanoma. Am J Pathol 159: 893-903

Skobe M, Hawighorst T, Jackson DG, Prevo R, Janes L, Velasco P, Riccardi L, Alitalo K, Claffey K, Detmar M (2001b) Induction of tumor lymphangiogenesis by VEGF-C promotes breast cancer metastasis. Nat Med 7: $192-198$

Stacker SA, Achen MG, Jussila L, Baldwin ME, Alitalo K (2002a) Lymphangiogenesis and cancer metastasis. Nat Rev Cancer 2: 573-583

Stacker SA, Baldwin ME, Achen MG (2002b) The role of tumor lymphangiogenesis in metastatic spread. FASEB J 16: 922-934

Stacker SA, Caesar C, Baldwin ME, Thornton GE, Williams RA, Prevo R, Jackson DG, Nishikawa S-I, Kubo H, Achen MG (2001) VEGF-D promotes the metastatic spread of tumor cells via the lymphatics. Nat Med 7: 186-191

Stacker SA, Stenvers K, Caesar C, Vitali A, Domagala T, Nice E, Roufail S, Simpson RJ, Moritz R, Karpanen T, Alitalo K, Achen MG (1999) Biosynthesis of vascular endothelial growth factor-D involves proteolytic processing which generates non-covalent homodimers. J Biol Chem 274: $32127-32136$ 
Stacker SA, Williams RA, Achen MG (2004) Lymphangiogenic growth factors as markers of tumor metastasis. APMIS 112: 539-549

Sun W, Haller DG (2005) Adjuvant therapy of colon cancer. Semin Oncol 32: $95-102$

Ueda M, Terai Y, Yamashita Y, Kumagai K, Ueki K, Yamaguchi H, Akise D Hung Y-C, Ueki M (2002) Correlation between vascular endothelial growth factor-C expression and invasion phenotype in cervical carcinomas. Int J Cancer 98: $335-343$

Veikkola T, Jussila L, Makinen T, Karpanen T, Jeltsch M, Petrova TV, Kubo H, Thurston G, McDonald DM, Achen MG, Stacker SA, Alitalo K (2001) Signalling via vascular endothelial growth factor receptor-3 is sufficient for lymphangiogenesis in transgenic mice. EMBO J 20: 1223-1231

Von Marschall Z, Scholz A, Stacker SA, Achen MG, Jackson DG, Alves F, Schirner M, Haberey M, Thierauch KH, Wiedenmann B, Rosewicz S (2005) Vascular endothelial growth factor-D induces lymphangiogenesis and lymphatic metastasis in models of ductal pancreatic cancer. Int $J$ Oncol 27: 669-679
White JD, Hewett PW, Kosuge D, McCulloch T, Enholm BC, Carmichael J, Murray JC (2002) Vascular endothelial growth factor-D expression is an independent prognostic marker for survival in colorectal carcinoma. Cancer Res 62: $1669-1675$

Wolmark N, Wang J, Mamounas E, Bryant J, Fisher B (2001) Preoperative chemotherapy in patients with operable breast cancer: nine-year results from National Surgical Adjuvant Breast and Bowel Project B-18. J Nat Cancer Inst Monogr No. 30, 96-102

Wong SY, Haack H, Crowley D, Barry M, Bronson RT, Hynes RO (2005) Tumor-secreted vascular endothelial growth factor- $\mathrm{C}$ is necessary for prostate cancer lymphangiogenesis, but lymphangiogenesis is unnecessary for lymph node metastasis. Cancer Res 65: $9789-9798$

Yokoyama Y, Charnock-Jones DS, Licence D, Yanaihara A, Hastings JM, Holland CM, Emoto M, Umemoto M, Sakamoto T, Sato S, Mizunuma H, Smith SK (2003) Vascular endothelial growth factor-D is an independent prognostic factor in epithelial ovarian carcinoma. $\mathrm{Br}$ J Cancer 88: 237 -244 